\title{
Intervenciones de regeneración en áreas turísticas de litoral. Una propuesta de homogeneización terminológica
}

\author{
Moisés Simancas Cruz ${ }^{1}$ | Rafael Temes Cordovez ${ }^{2}$ | Alicia García Amaya ${ }^{3}$ \\ Recibido: 14-02-2019 | en su versión final: 15-02-2020
}

Resumen Al igual que en la ciudad residencial, el envejecimiento y la obsolescencia de los espacios urbanos que soportan la actividad turística demandan soluciones que garanticen el mantenimiento, e incluso, incremento de su competitividad. Por ello, la intervención en los espacios privados (establecimientos turísticos y equipamientos de servicio y ocio) y públicos de las áreas vacacionales de litoral se ha convertido en un eje estructural de las políticas públicas. Sin embargo, a pesar de la experiencia que hoy se tiene en materia de intervención sobre la ciudad existente, resulta frecuente el uso con escaso rigor, una gran ambigüedad y cierto grado de discrecionalidad, de los términos que describen los distintos y diversos tipos de actuaciones. Esto suscita con frecuencia bastantes dudas respecto a la precisión de las denominaciones, a la vez que pugna con las exigencias mínimas del principio de seguridad jurídica y de la objetividad exigible a la Administración Pública. El objetivo principal de este trabajo es identificar y sistematizar la diversidad de términos utilizados para referirse al conjunto de intervenciones físicas que se acometen en la etapa de regeneración de los espacios urbano-turísticos de litoral, con el fin de proponer una terminología homogénea y un lenguaje común. Para ello, las referencias contempladas en las distintas normativas que articulan la política pública de renovación del destino Islas Canarias (España) han servido de base para la propuesta de homogeneización de las definiciones, así como para dotarla de una dimensión aplicada y no especulativa. Asimismo, se parte de una revisión sistemática de la literatura, que ha permitido la categorización de la producción científica en torno a la discusión sobre los términos habitualmente utilizados en materia de intervención sobre los espacios urbanos consolidados.

Palabras clave: islas Canarias; renovación; espacio urbano-turístico; terminología

Citación

Simancas, M. et al. (2020). Intervención de regeneración en áreas turísticas de litoral. Una propuesta de homogeneización terminológica, ACE: Architecture, City and Environment. 15(43), 7037. DOI: http://dx.doi.org/10.5821/ace.15.43.7037

\begin{abstract}
${ }^{1}$ Dr. Geógrafo. Profesor Titular de Geografía Humana de la Universidad de La Laguna (ORCID: 0000-00020337-0424: WOS Researcher ID: R-6971-2018, Scopus autor ID: $57194216449{ }^{2}$ Dr. Arquitecto. Profesor Contratado Doctor de Urbanística y Ordenación del Territorio de la Universidad Politécnica de Valencia (ORCID: 0000-0002-5604-4892, WOS Researcher ID: D-5693-2016; Scopus autor ID: 56035209900), ${ }^{3}$ Arquitecta. Máster en Arquitectura Avanzada, Paisajismo, Urbanismo y Diseño (ORCID: 0000-0003-31144712, Scopus Author ID: $\underline{57200628983})$. Correo de contacto: $\underline{\text { msimancas@ull.es }}$
\end{abstract}




\title{
Interventions for renovation of coastal tourism destinations. A proposal for terminological homogenization
}

\begin{abstract}
As in residential areas, ageing and obsolescence of urban fabrics that hold tourism activities require measures that ensure maintenance and even increase of competitiveness. For this reason, intervention in public and private spaces (such as tourism accommodation, services and leisure facilities, etc.) of coastal holiday destinations have become a structural axis of public policies. However, despite the experience acquired with the intervention in pre-existing cities, terminology used to describe the different kinds of proceedings is frequently misused. The lack of accuracy in the use of terms that describe different kinds of interventions in tourism areas and facilities affect the principle of legal certainty and the objectivity enforceable to Public Administration. The purpose of this paper is to identify and systematize the diversity of terms frequently used to describe physical interventions for the regeneration of coastal urban destinations, with the aim of proposing a common and homogeneous terminology. This work is based on the references contained in regulations related to the renovation of the tourism destination Canary Islands (Spain). The selection of terms has a practical and nonspeculative dimension, based on a deep and systematized revision of bibliography. The result is a categorization of the scientific production related to the discussion of terms applied to interventions in consolidated urban areas.
\end{abstract}

Keywords: Canary Islands; renovation; urban-tourist space; terminology

\section{Introducción}

La definición de destinos turísticos establecida por la Organización Mundial del Turismo (2007) se refiere a aquellos ámbitos territoriales fácilmente reconocibles con límites geográficos o administrativos que los turistas visitan y en la que permanecen durante su viaje. De esta manera, los destinos adquieren un papel clave en el sistema territorial del turismo, en cuanto en ellos no sólo pernoctan los turistas, sino que constituyen los escenarios donde desarrollan gran parte de las actividades durante su estancia. Esta visión geográfica determina que una de las características esenciales de los espacios urbano-turísticos de litoral es la concentración espacial de establecimientos de alojamiento turístico, especialmente vacacionales, equipamientos, infraestructuras y dotaciones de ocio y servicios. Esta cualidad, les diferencia de los espacios urbanos no turísticos.

Como cualquier espacio urbano, los turísticos alcanzan estados de madurez, estancamiento o consolidación en función de la terminología de los distintos modelos evolutivos descriptivospredictivos utilizada dentro de la literatura turística. Ello supone que los destinos logran una plenitud vital y óptima, en la medida en que supone, entre otras cuestiones, que han consolidado un producto, una marca, una actividad sustancial, una trayectoria (experiencia), un reconocimiento y valoración internacional, una capacidad de resiliencia, así como la involucración de un elevado número de stakeholders (Blanco, 2012). Sin embargo, esta etapa puede ser también el paso previo a su declive (Butler, 1980; Aguiló, Alegre y Sampol, 2002) y si se prolonga, decadencia (Antón, 
Fernández y Reverté, 2008; Simancas, 2015). Ello conlleva una pérdida de competitividad, con la consiguiente reducción de la capacidad de atracción y cuota de mercado respecto a otros destinos.

Gran parte de las áreas turísticas del litoral español que surgieron con la apertura de mercados de la década de los sesenta, en la actualidad tienen entre cincuenta y sesenta años. En su mayoría, padecen situaciones de obsolescencia, debido a que su morfología, utilidad o funcionalidad se vuelve insuficiente o superada por los gustos, motivaciones y exigencias de una demanda cambiante y, por ende, a las nuevas tendencias del mercado (Simancas, 2015). Ello tiene un efecto negativo sobre los turistas, visitantes y residentes de tales áreas.

Sin embargo, esta situación determinista y lineal no resulta tan fácilmente probable y, en ningún caso, es un hecho irreversible, unidireccional, consumado y automático (Agarwal, 1997 y 2002; Priestley y Mundet, 1998; Knowles y Curtis, 1999; Butler, 2012; Ivars, Rodríguez y Vera, 2013). Además, en la medida en que el producto vacacional de litoral sigue siendo la motivación principal de los turistas europeos (Vera et al., 2011), su papel hegemónico se mantiene vigente, aunque requiera transformaciones, ajustes y adaptaciones. Así, en coherencia con la hipótesis positivista de Aguiló y Alegre (2004), resulta posible la regeneración de los destinos turísticos en declive, en cuanto cualquier derivación crítica puede ser corregida estructuralmente (Camisón y Monfort, 1998; Agarwal, 2002; Ivars, Rodríguez y Vera, 2013). Al respecto, Ivars (2003) señala que la madurez de los destinos turísticos sería la fase que requiere capacidad de adaptación a los cambios y desde la que se puede transitar hacia la decadencia, pero también reorientarse hacia la reinvención mediante políticas de renovación, reestructuración y recualificación. Para ello, siguiendo el proceso secuencial de generación-degeneración-regeneración de destinos turísticos, las intervenciones "re-" se revelan como básicas y estructurales en esta última etapa.

Sin embargo, en este punto surge el problema: dada la amplia diversidad de tipologías, intensidades e impactos de las acciones y procesos de regeneración, los términos "re-" son utilizados de forma simultánea, indistinta y ambigua, como si se tratara de sinónimos y, en ocasiones, de manera equívoca (Vera et al., 2011). Ello hace relevante abordar dos cuestiones: por un lado, desde una perspectiva teórico-analítica, analizar el ciclo de evolución de los destinos como marco para interpretar su situación actual y, sobre todo, sus necesidades de adaptación y regeneración; por otro, desde una perspectiva aplicada y propositiva, identificar y sistematizar las estrategias de intervención acometidas en los espacios urbano-turístico de litoral, con el fin de plantear una terminología homogénea. Este trabajo se inserta en esta última cuestión.

El objetivo principal de este trabajo es identificar y sistematizar la diversidad de términos "re-", que son utilizados para referirse al conjunto de intervenciones físicas que se acometen en la etapa de regeneración de los espacios urbano-turísticos de litoral, con el fin de proponer una terminología homogénea y un lenguaje común. Para ello, tras la revisión sistemática de la literatura, se expone la producción científica relativa a la discusión sobre los términos habitualmente utilizados en materia de intervención sobre los tejidos construidos, con especial énfasis en los ámbitos turísticos. En esta propuesta de homogeneización de las definiciones ha sido útil, al menos para dotar de una dimensión aplicada y no especulativa a los diferentes enunciados generales, las referencias contempladas en las distintas normativas que articulan la política pública de renovación del destino Islas Canarias (España). Esta se inició con el Decreto 4/2001, de 12 de enero, por el que se acordó la formulación de las Directrices de Ordenación General y las del Turismo, continuó con la Ley 19/2003, prolongándose hasta la actualidad con la Ley 9/2015, de modificación de la Ley 2/2013, de 29 de mayo, de Renovación y Modernización Turística de Canarias. Estas normas han planteado la regeneración de los espacios privados (establecimientos de alojamiento turístico y los equipamientos de ocio y servicios) y públicos, así como la estrategia estructural de la política pública turística. 


\section{Planteamiento del problema. La imprecisión de los términos relativos a las intervenciones en los espacios urbanos}

El período transcurrido entre 1960 y 1980 en España ha sido el intervalo en el que, hasta la fecha, se han dado los mayores crecimientos en número de viviendas (Rubio del Val, 2011). Una de cada tres viviendas/alojamientos en el país fue construida durante esos veinte años (Temes, 2017). Este building-boom ha condicionado necesariamente el futuro de los entornos urbanos. Así, desde hace unos años, se comenzó a tantear un marco jurídico específico que contara con la ciudad existente y deteriorada, para integrarla dentro de las políticas de ordenación del suelo. Desde el inicio de la década de los 2000, este tipo de intervenciones públicas han comenzado a plantearse en las áreas turísticas maduras de litoral; prueba de ello es, por ejemplo, que el Plan del Turismo Español 20082012 recoge los proyectos extraordinarios de recualificación de destinos maduros entre sus programas y líneas de acción. Estas estrategias han sido analizadas, entre otros, por Camisón y Monfort (1998), Oreja (2000), Socías (2000), Donaire y Mundet (2001), Exceltur (2003), Mirallave (2004), Antón (2005 y 2011), Navarro (2006), García (2009), Villar (2009 y 2016), Perelli del Amo y Prats (2007), Santos y Fernández (2010), Llorca y Sosa (2010), Vera y Baños (2010), Vera, Rodríguez y Capdepón (2010), Simancas (2010, 2011, 2012, 2015 y 2016), Beas (2012), González (2012), Rodríguez y Santana (2013), Rodríguez y Such (2014), Medina, Medina y Sánchez (2016), Temes (2017), Rodríguez y Rodríguez (2018) y Falcón (2019). Sin embargo, como ya se ha planteado, la aplicación de los términos "re-" a los espacios urbano-turísticos de litoral no está exenta de complicaciones.

En primer lugar, las expresiones generalmente empleadas para referirse a las intervenciones en las ciudades residenciales, donde el amplio frente edificado ha anticipado el debate sobre el envejecimiento urbano (Temes, 2007), se han reproducido de manera mimética a las áreas turísticas consolidadas de litoral. Se trata de expresiones de uso frecuente en el ámbito de la construcción y el urbanismo, que se han extrapolado a otras disciplinas para definir acciones similares. Sin embargo, los espacio urbano-turísticos son ámbitos territoriales especializados, con características propias y formas singulares de urbanización (Mullins, 1994) que las distinguen de los espacios urbanos tradicionales. Así, cada área "responde a una práctica urbana singular, funcional y estructuralmente diferenciada de la ciudad convencional” (Antón, 1998, pág. 28), hasta el punto que suelen presentar "densidades e intensidades de consumo y de ocupación del territorio muy diversificadas, en función del modelo de producto que ofrezca cada ámbito y de la escala a que se establezca el consumo" (Barrado, 2004, pág. 47). Del mismo modo, como plantean Beritelli et al. (2014) y Chapman y Light (2016), las áreas turísticas se conforman por la agregación de zonas situadas en diferentes etapas de los ciclos de vida según la terminología de los distintos modelos evolutivos descriptivos-predictivos.

En segundo lugar, la precisión terminológica de las intervenciones en las ciudades residenciales no ha sido una cualidad sobresaliente. Como afirman Álvarez \& Camerin (2019), los conceptos de raíz urbanística se van forjando al amparo de prácticas concretas, de cuyos procesos, durante o al final de su recorrido, se derivan términos que acaban ostentando la capacidad de ser referenciados en su sentido más amplio. Además, en muchas ocasiones, esta génesis basada en la praxis ha desatendido la precisión terminológica. Ello ha sido consecuencia, entre otras cuestiones, de la falta de coordinación entre los instrumentos urbanísticos de intervención en la ciudad, las políticas de subvención de la intervención edificatoria y urbana, así como las consideraciones derivadas del reconocimiento del patrimonio urbano. Bien es cierto que algunos trabajos han aportado avances en la línea de intentar deslindar los términos en espacios residenciales, planteando propuestas sistemáticas y globales, como es el caso de Robert \& Sykes (2000) y Moya \& Díez (2012), o definiciones precisas de alguno de los términos, en un intento de entender su verdadera dimensión (Mansfield, 2002; Rubio del Val, 2011; García, 2017; Álvarez \& Camerin, 2019; Castrillo et al., 2019). No obstante, a ello, numerosos autores siguen empleando de manera yuxtapuesta términos próximos 
que producen confusión (Castrillo et al., 2014), lo que incrementa la dificultad para acordar un mismo término (Robert \& Sykes, 2000), provocando una indeterminación conceptual y metodológica (Moya y Díez, 2012; Gaja, 2015).

El resultado es que, al igual que pasa en la ciudad residencial, el uso de términos "re-" suscita con frecuencia bastantes dudas en la precisión de sus denominaciones. Se trata de expresiones excesivamente genéricas, arbitrarias, ambiguas, imprecisas y con un cierto grado de discrecionalidad. Además, presentan una difícil medición y concreción en cuanto a su contenido. Todo ello pugna con las exigencias mínimas del principio de seguridad jurídica y de la objetividad exigible a la Administración Pública.

Aunque diversos trabajos han abordado los procesos de renovación de las áreas turísticas de litoral en los últimos años, son pocos los dedicados a intentar deslindar las diferencias entre los términos y matizar las peculiaridades de las intervenciones en el ámbito turístico. En este proceso de aproximación a las definiciones ha sido útil, al menos para ordenar los tipos de intervenciones, la propuesta realizada por Simancas (2015); ésta clasifica las acciones y procesos de aplicación sobre el destino turístico (a diferente escala) y la estructura del área turística o sobre partes concretas (establecimientos turísticos de alojamiento, infraestructuras y equipamientos), según su alcance, intensidad y capacidad de transformación en cada fase o etapa del ciclo secuencial de generación $\rightarrow$ degeneración $\rightarrow$ regeneración del destino turístico (Figura 1).

Figura 1. Estrategias de intervención en el ciclo de generación-degeneración-regeneración de los destinos turísticos consolidados de litoral

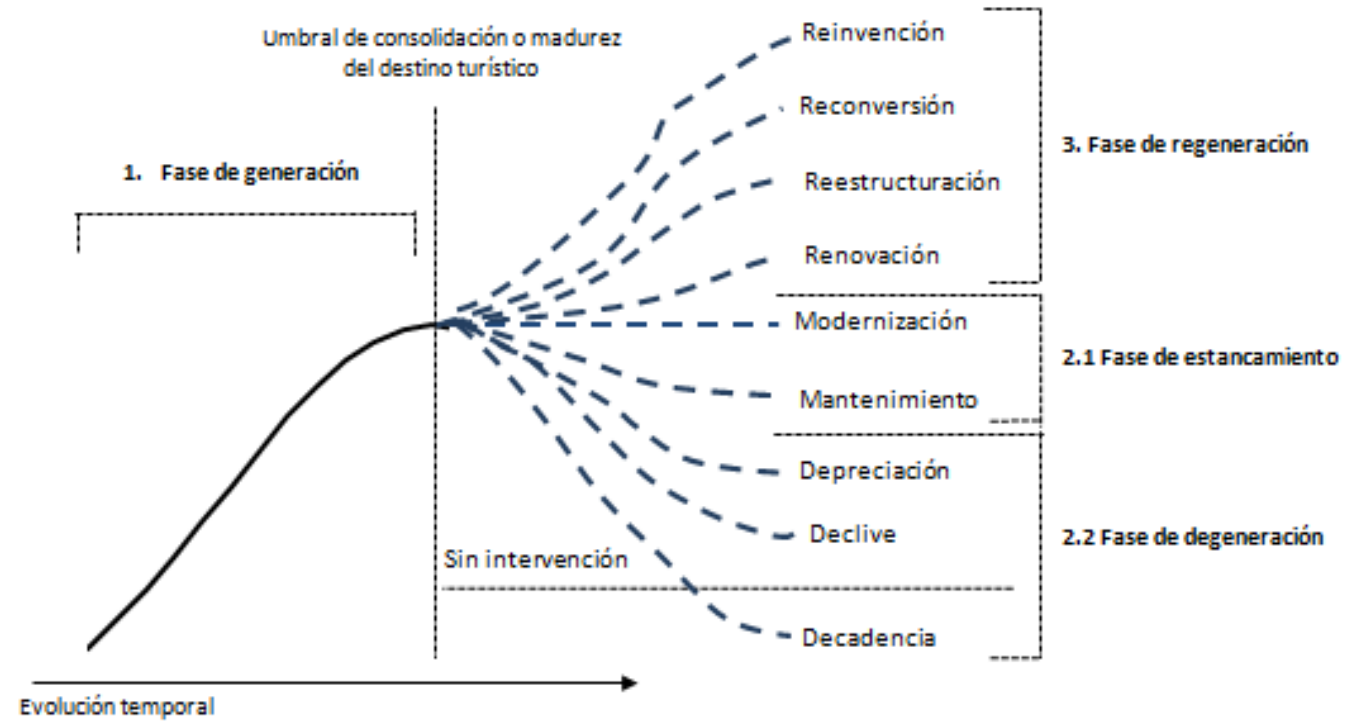

Fuente: Simancas (2015).

Un primer grupo de denominaciones alude a intervenciones y estrategias dirigidas al "mantenimiento" y, en el mejor de los casos, "modernización" de las áreas turísticas de litoral (García, 2009). Se trata de acciones y procesos de tipo "singular" o blandas (Navarro, 2006), a modo de acciones de cosmética, "lavados de cara", "lifting”, "maquillaje” y/o marketing hacia el exterior o para autoconsumo de las sociedades locales y, en el mejor de los casos, a su actualización o rejuvenecimiento (Butler, 1980 y 2012; Getz, 1992; Simancas, 2010; Navarro, 2006). Constituyen soluciones paliativas y viables únicamente a corto plazo, provocando que las áreas turísticas se 
mantengan en la fase de estancamiento (Figura 1). Por tanto, supone continuar con las pautas tendenciales de desarrollo turístico de "modelos pretéritos" (Santos y Fernández, 2010).

El segundo grupo se refiere al conjunto sistémico de estrategias susceptibles de ser aplicadas en la etapa de reorientación definida por Agarwal (1997), que se ubica entre la de estancamiento y postestancamiento (Priestley y Mundet, 1998). Su implementación ha pretendido "introducir dinámicas de cambio apoyadas en nuevos criterios y paradigmas" (Santos y Fernández, 2010), dirigidas a generar transformaciones estructurales en el modelo territorial-turístico. El fin último ha sido adaptarlo a las nuevas tendencias y, sobre todo, modificar su dinámica negativa de degeneración (Figura 1), logrando su "revitalización" (Oreja, 2000) o "reposicionamiento" competitivo (Camisón y Monfort, 1998).

El tercer grupo de intervenciones abarca una diversidad y gradiente de políticas, programas, planes y proyectos que abarca un amplio y diverso conjunto de términos "re". En función de su intensidad e impacto - entendido como un cambio-, éstos han comprendido desde las dirigidas a la "renovación” y "reestructuración” del destino y/o áreas turísticas (Antón, 1998, 2005 y 2011; Santos y Fernández, 2010; Vera, Rodríguez y Capdepón, 2010; González, 2012; Vera y Baños, 2013), hasta las que pretenden una cierta "revolución", en cuanto implican una transformación total del modelo turístico. En estos casos, se trata de proceder a su "reconversión” y "reorientación” (Agarwall, 2002; Exceltur, 2003; Perelli del Amo y Prats, 2007; Rullán, 2008), e incluso, en los casos extremos, “reinvención” (Baum, 1998; Simancas, 2015).

\section{Metodología y materiales utilizados}

La metodología empleada en este artículo se divide en dos partes atendiendo a los objetivos enunciados. En una primera instancia, se procedió a realizar un análisis clásico de revisión sistemática de la literatura (SLR), con el fin de valorar la existencia de trabajos previos centrados en determinar las diferencias entre los términos "re-" de forma general, y especialmente en los espacios urbano-turísticos. Junto con los estudios de mapeo sistemático (Systematic Mapping Study, SMS), las SLR son consideradas como estudios de carácter secundario. Como comenta Celdrán-Bernabéu et al. (2018), un SMS no es una SLR, a pesar de sus similitudes. Una de las diferencias principales radica en las preguntas de investigación: mientras que las SLR responden a preguntas específicas y agregan resultados relacionados con las preguntas de investigación, los SMS responden a preguntas más abiertas, relacionadas con tendencias, a la vez que se limita a identificar y clasificar estudios primarios en subtemas. Por lo tanto, el análisis, la interpretación y la generalización de los hallazgos están más focalizados (Celdrán-Bernabéu et al., 2018). Conforme a este planteamiento se han diseñado cuatro peguntas de investigación, en base a las que se formularon los criterios de búsqueda que se aplicaron con posterioridad (Tabla 1).

Tabla 1. Preguntas de la investigación

\begin{tabular}{|l|l|}
\hline Pregunta de investigación & Objetivo \\
\hline $\begin{array}{l}\text { ¿Cómo han evolucionado en el campo del turismo } \\
\text { las investigaciones que tratan de conceptualizar y } \\
\text { deslindar los términos "re-“? }\end{array}$ & $\begin{array}{l}\text { Conocer la evolución de la investigación entre en el } \\
\text { período 2000-2018, así como su distribución } \\
\text { (artículos, capítulos de libro y conferencias). }\end{array}$ \\
\hline $\begin{array}{l}\text { ¿Cuáles son las palabras clave más utilizadas? } \\
\text { ¿Cuál es la evolución y distribución geográfica de las las palabras clave más utilizadas en los } \\
\text { publicaciones? }\end{array}$ & $\begin{array}{l}\text { Conocer la evolución de las investigaciones de } \\
\text { acuerdo de acuerdo a su procedencia geográfica. }\end{array}$ \\
\hline
\end{tabular}

Elaboración propia

ACE, 15 (43) CC BY-ND 3.0 ES | UPC Barcelona, España | Intervenciones de regeneración en áreas turísticas de litoral. 
En coherencia con lo planteado por Granda et al. (2013) y Celdrán-Bernabéu et al. (2018), la elección de Scopus queda justificada de acuerdo a su mayor cobertura en revistas científicas relacionadas con el turismo. Los procedimientos de búsqueda en un SRL constituyen uno de los puntos más importantes, pues de ellos depende en buena parte los resultados obtenidos. En nuestro caso, hemos realizado diferentes procesos de búsqueda que ha dado paso a tres criterios en función el grado de acotación que necesitábamos administrar:

\section{Criterio 1 (C1)}

Se trata de una búsqueda más general y extensa en la que no se establece la distinción entre intervenciones en el ámbito residencial o turístico.

- Las investigaciones quedan acotadas a las subáreas: Arts and Humanities; Social Sciences; Environmental Science; Engineering. Esta decisión es fundamental para no distorsionar la muestra obtenida. Dado el uso equivalente de algunos de estos términos (rehabilitación, renovación, etc.) en el campo biosanitario, se tiene que hacer una acotación de las subáreas de búsqueda.

- En el título, resumen o palabras clave debe figurar alguno de términos renewal, redevelop, renovation o rehabilitation.

- Se limita la búsqueda a aquellas investigaciones que en las palabras clave al menos contengan alguno de los términos siguientes: rehabilitation, urban renewal, urban regeneration, repair, maintenance, urban planning, urban area, urban development, planning o renovation. Estas palabras claves han sido extraídas de la base de datos Scopus como las más frecuentes en la búsqueda realizada en cada caso.

\section{Criterio $2(\mathrm{C} 2)$}

Se trata de un criterio más restrictivo y concreto, al ceñirse sólo al ámbito turístico.

- Las investigaciones quedan acotadas a las subáreas: Arts and Humanities; Social Sciences; Environmental Science; Engineering

- $\quad$ En el título, resumen o palabras clave debe figurar alguno de los siguientes de C1 y además los de tourism o tourist.

- Se limita la búsqueda a aquellas investigaciones que en las palabras clave contengan alguno de los términos de C1 y además los de tourism, tourism development, gentrification, heritage tourism, tourist destination, tourism management, tourist attraction, ecotourism, tourism economics, urban tourism o tourist accommodation.

Criterio 3 (C3)

Se trata de una búsqueda que complementa al C1 y al C2

- Se limita la búsqueda a aquellas investigaciones que en las palabras clave contengan alguno de los términos de C1 o C2 y además de los de epistemology, terminology, concept, definition, typology o state of the art.

El trabajo de búsqueda se realizó entre diciembre de año 2019 y enero de 2020.Tras la aplicación del Criterio 1 se devolvieron 9.771 resultados. Estos se redujeron a 393 al aplicar el Criterio 2.

Si sobre el Criterio 1 aplicamos el 3 (C1+C3), obtenemos 951 resultados. A su vez, si lo aplicamos sobre el Criterio 2 (C2+C3), entonces obtenemos 45 resultados. Una vez acotados estos resultados, procedemos a realizar una revisión manual de los títulos de las aportaciones para localizar trabajos centrados en proponer una taxonomía o profundizar en las diferencias entre los términos en "re-" si bien el trabajo se cierra finalmente sin localizar ninguno. Al menos conforme a la búsqueda realizada y atendiendo a los trabajos indexados en la base Scopus, no encontramos ningún trabajo que pudiera servir de marco de referencia concreto para nuestro propósito.

ACE, 15 (43) CC BY-ND 3.0 ES | UPC Barcelona, España | Intervenciones de regeneración en áreas turísticas de litoral. 7 Una propuesta de homogeneización terminológica. DOI: http://dx.doi.org/10.5821/ace.15.43.7037 


\section{Resultados de la revisión sistemática de términos}

Si hacemos una comparación cronológica basada en los años de publicación de las investigaciones podemos observar como la aplicación del C1 de carácter más genérico nos devuelve cuatro aportaciones desde 1969, estableciendo varios picos de intensidad en los años 1994 (199 aportaciones), 2006 (343) y 2012 (599) (Figura 2).

Figura 2. Evolución de las publicaciones según el criterio 1

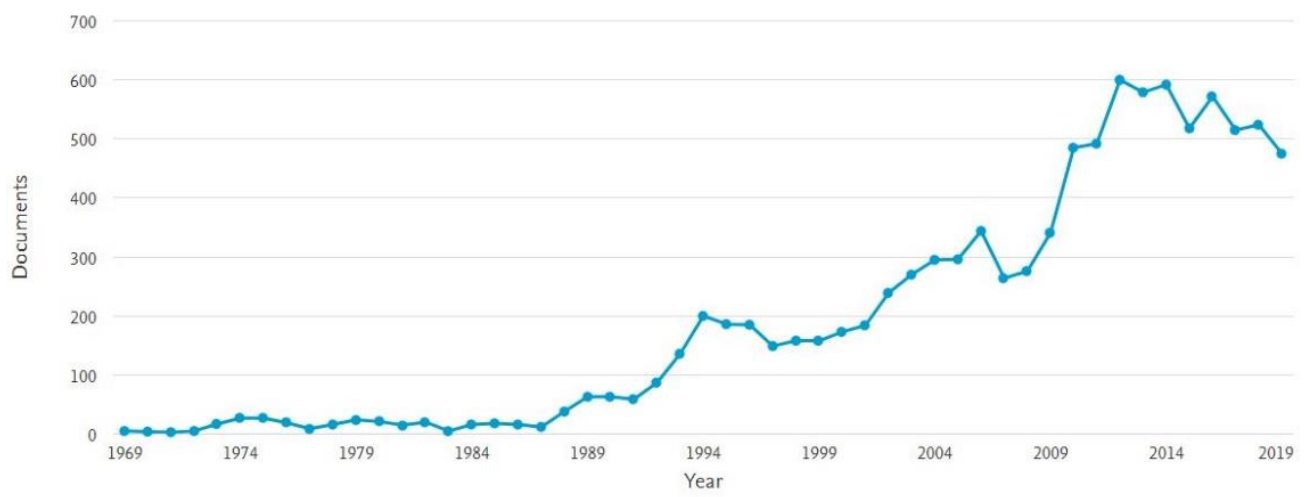

Fuente: Scopus. Elaboración propia

La aplicación de C2 permitió identificar la primera investigación una década más tarde, en 1980. En el año 2000 aparecen 11 aportaciones y 40 en 2013. En los últimos años se percibe un retroceso, aunque parece volver a remontar a partir de 2018 (Figura 2).

Figura 2. Evolución de las publicaciones según el criterio 2

50

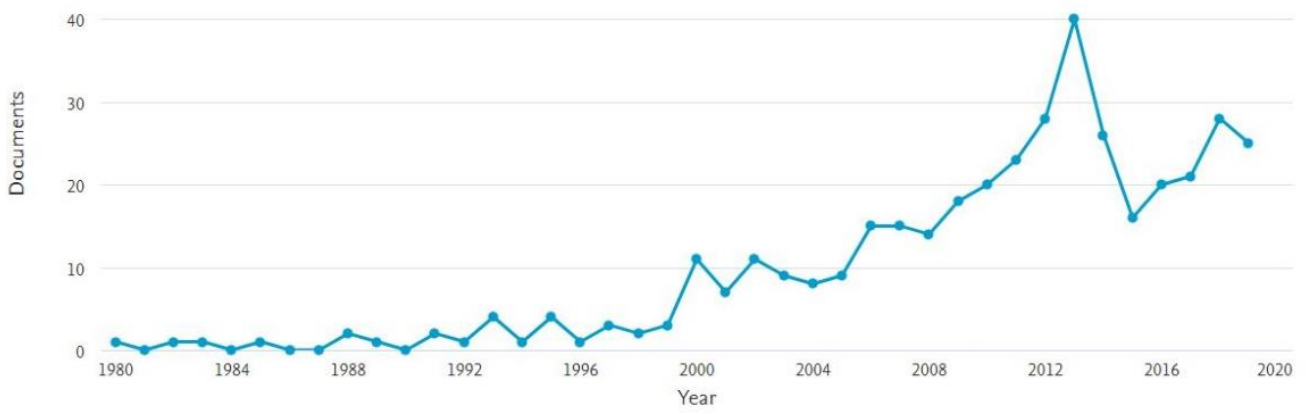

Fuente: Scopus. Elaboración propia.

En relación con la procedencia de los trabajos en el caso de la aplicación del Criterio 1 (Figura 3) el $44 \%$ de los trabajos provienen de Estados Unidos, Reino Unido y Canadá. En el caso de los trabajos estadounidenses y canadienses entre un 46 y un 48\% están adscritos al área de ingeniería muy vinculada a las Infraestructuras y el Transporte. Las Universidades de Toronto y la Purdue son las que más aportaciones hacen a esta línea de trabajos. En el caso británico, un 52\% de los artículos están adscritos al área de Ciencias Sociales, siendo la University College de Londres la de mayor producción.

ACE, 15 (43) CC BY-ND 3.0 ES | UPC Barcelona, España | Intervenciones de regeneración en áreas turísticas de litoral. 8 Una propuesta de homogeneización terminológica. DOI: http://dx.doi.org/10.5821/ace.15.43.7037 
Figura 3. Evolución de las publicaciones del criterio 1 según el país

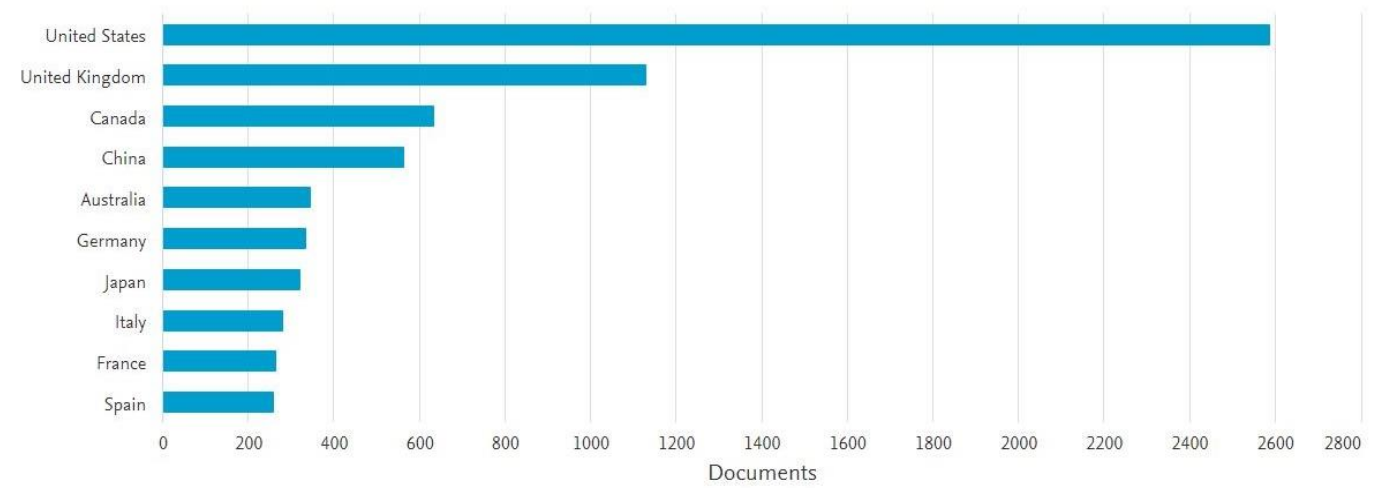

Fuente: Scopus. Elaboración propia.

En el caso del Criterio 2 acotado al campo del turismo (Figura 4), el 36\% de los trabajos provienen de Estados Unidos, Reino Unido y España. Los trabajos estadounidenses en más de un 61\% quedan adscritos al área de Ciencias Sociales; lo mismo sucede en el caso británico (74\%) y el caso español (60\%). La Université des Sciences et Technologies de Lille y la Universidad Autónoma de Barcelona son las que aportan más documentos por filiación. La inmensa mayoría de los artículos están publicados en revistas de un perfil más urbano que turístico. Las principales revistas que se recogen artículos de este tipo son Journal of Urban History, Planning, y Urban Studie. El Boletín de la Asociación de Geografía Española y Architecture, City and Environment son las revistas que recogen más artículos en esta línea en España.

Figura 4. Evolución de las publicaciones según el criterio 2

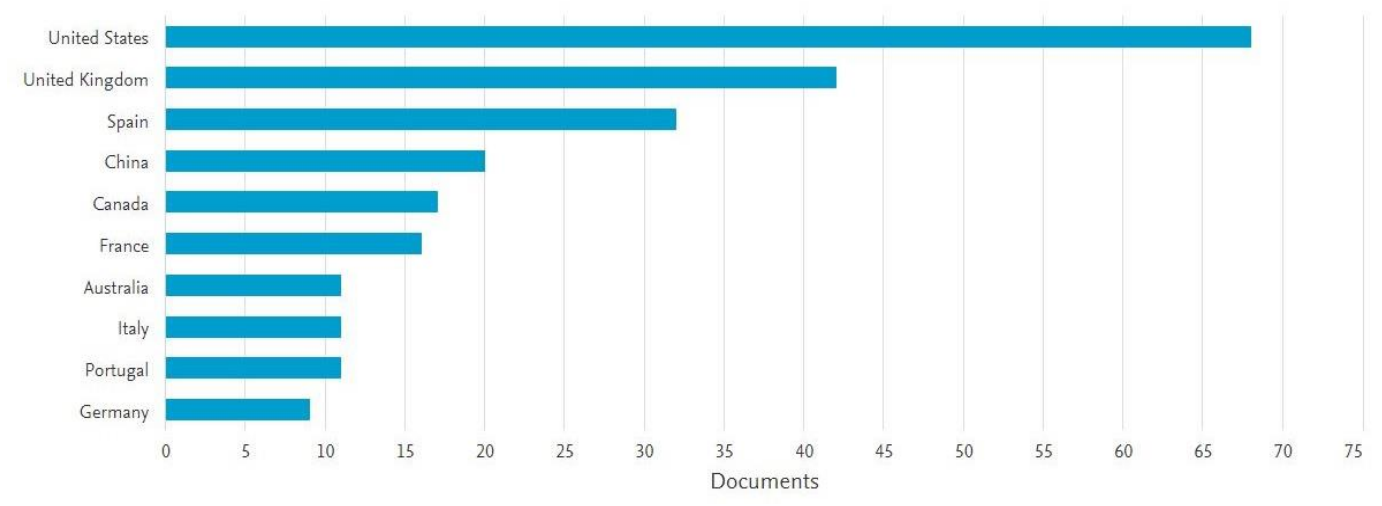

Fuente: Scopus. Elaboración propia.

Como conclusión de la SLR podemos señalar que la producción científica en torno a los temas relacionados con los términos "re-" se incrementó a partir de finales de los años noventa del siglo pasado. Las investigaciones estadounidenses y británicas son las más frecuentes, aunque con un cierto sesgo tecnológico que las alejas de nuestros intereses. España es el tercer país en producción cuando acotamos el campo de búsqueda a la actividad turística. La diferente proporción de aportaciones en el ámbito residencial respecto al turístico es notable, no pudiéndose localizar aún un núcleo de reflexión propio y singular característico de los destinos turísticos. Tampoco se localizan aportaciones centradas específicamente en deslindar las diferencias entre los términos en "re-". 


\section{Propuesta de ordenación terminológica de las intervenciones "re-" en las áreas turísticas de litoral}

Una de las principales conclusiones de la anterior revisión bibliográfica valida lo indicado en el apartado de planteamiento del problema de este trabajo. La mayor proliferación de términos y, por tanto, la necesidad de deslindar definiciones con precisión, se da dentro de las acciones físicas. Es lógico que así sea pues se trata de expresiones de uso frecuente en el ámbito de la construcción y el urbanismo, que luego han ido extrapolándose a otras disciplinas para definir acciones similares. En este sentido, la aplicación de términos utilizados habitualmente en los procesos de intervención en las ciudades, el uso de términos heredados de otras lenguas y el empleo de expresiones ambiguas utilizadas por las distintas disciplinas que convergen en torno a la ciudad, han dado como resultado un panorama confuso desde el punto de vista de la precisión epistemológica.

En la primera fase de la metodología empleada en la que usamos un SLR no localizamos ninguna aportación que pudiera servir de referencia para guiar los pasos en la fase siguiente. Como apunta Villalobos (2013) no todas las aportaciones, ni siquiera las mejores, terminan depositándose en las bases indexadas. En nuestro caso, el texto más completo de la literatura científica dentro del campo del urbanismo es el de Moya \& Díez (2012). Este propone una estructura organizativa de las intervenciones física en el espacio público y privado que consideramos útil para apoyar nuestra propuesta de ordenación terminológica para el caso de los destinos turístico de litoral.

\subsection{Acciones y procesos de intervención en las áreas turísticas de litoral}

En este amplio conjunto de formas de actuar sobre los tejidos turísticos consolidados al que hemos aludido, siguiendo a Moya y Díez (2012), podemos decir que en toda intervención puede distinguirse entre "acciones" y "procesos". Las acciones hacen referencia a cuatro tipos:

a) Las consideradas como FísICAS. Corresponden a la ejecución material de la intervención, identificándose con lo que en la normativa urbanística se ha denominado habitualmente como obras -tanto mayores como menores- en edificios y de infraestructuras en el espacio público. Estas acciones se clasifican en función del grado de permanencia del sustrato existente (con o sin demoliciones), su grado de transformación volumétrica (con o sin aumento de volumen), y el grado de transformación de su organización interna (con o sin reorganización interna).

b) Las consideradas como TERRITORIALES. Se refiere a aquellas que tienen la vocación de mejorar el entorno del espacio urbano-turístico, recuperando el territorio y el paisaje que, en ocasiones, supuso el sustento inicial del desarrollo turístico. Así, suelen aplicarse en las zonas más antiguas y "pioneras", localizadas en los sectores de litoral más privilegiados desde el punto de vista del potencial turístico, con el fin de favorecer la recuperación de sus condiciones de competitividad (Simancas, 2015). Entre estas acciones hemos de distinguir aquellas que tratan de reintegrar los tejidos turísticos en su entorno rescatando y potenciando el paisaje original del asentamiento y los que tratan de hacer coherentes los asentamientos turísticos en los modelos de ordenación o vertebración territorial planteados. (Pié \& Rosa, 2014).

c) Las consideradas como ECONÓMICAS. Definidas como el conjunto de iniciativas encaminadas a transformar el modelo, pudiendo ser de diferente escala y de naturaleza pública y privada. Entre las acciones podemos mencionar las encaminadas a la implementación de cambios en los modelos de negocio, la estructura organizativa y de los recursos humanos, las formas de segmentación, los canales de comercialización y venta, los mecanismos de prestación de servicios, etc.; en este sentido, la renovación de los alojamientos turísticos y equipamientos de ocio y servicios se plantea en torno a actuaciones 
de innovación y de creación de nuevos productos que sean atractivos, diferenciados y que estén dirigidos a diversos segmentos de clientes.

d) Las consideradas como SOCIALES. Aquellas acciones dirigidas a paliar las posibles disfunciones y conflictos generados como consecuencia de los cambios en los modelos de explotación. Entre ellas destacamos las acciones dirigidas a abordar los problemas desencadenados por la falta de compatibilidad entre el uso residencial y el uso turístico, la gentrificación, etc.

Por su parte, los procesos abarcan aquellas iniciativas que, en su conjunto, encadenan las acciones a partir de una planificación, así como ofrecen métodos de cambio tanto en la realidad física como en los modelos turísticos. Tienen un carácter sectorial, cuando se centran sólo en un tipo de problemática, o integral cuando tratan de diseñar una intervención en la que se atiendan coordinadamente a varios tipos de déficit. En la definición de los procesos nos encontraremos con la relación existente entre regeneración, rehabilitación y renovación urbana, matizando también el significado de los procesos de reestructuración y remodelación.

En este punto, subrayamos el carácter del término "integral" que se usa en este texto. Cuando hablamos de renovación, reforma, mejora o actualización de la actividad turística o residencial, con frecuencia, de manera precipitada reducimos las opciones para centrarnos en actuaciones de carácter físico exclusivamente. Sin embargo, esta visión ha ido cambiando. Prueba de ello es que el punto 12.8 del Pacto de Ámsterdam, ya introducido y desarrollado en 2010 por el Documento de Referencia anexo a la Declaración de Toledo, incorpora los aspectos sociales, económicos, ambientales, espaciales o culturales junto con las intervenciones físicas. En los ámbitos turísticos no se emplea, generalmente, el término "integral" para describir los tipos de actuaciones. Sin embargo, también aquí las intervenciones no pueden entenderse como exclusivamente físicas, y es reclamable una visión global que atienda a la reducción de impactos, la reintegración paisajística o asuma posibles medidas para paliar las externalidades que los cambios pudieran generar en la población.

Basándonos en esta estructura, en la Tabla 2 tratamos de organizar los términos dentro de un esquema que los haga compatibles y con significados específicos, incorporando dicha visión integral en el espacio turístico. Ahora bien, no abordaremos la totalidad de los enfoques en este artículo, debido a las limitaciones del formato en el que lo presentamos, centrándonos exclusivamente en las intervenciones de tipo "físico".

Tabla 2. Propuesta terminológica de intervenciones de regeneración en las áreas turísticas de litoral

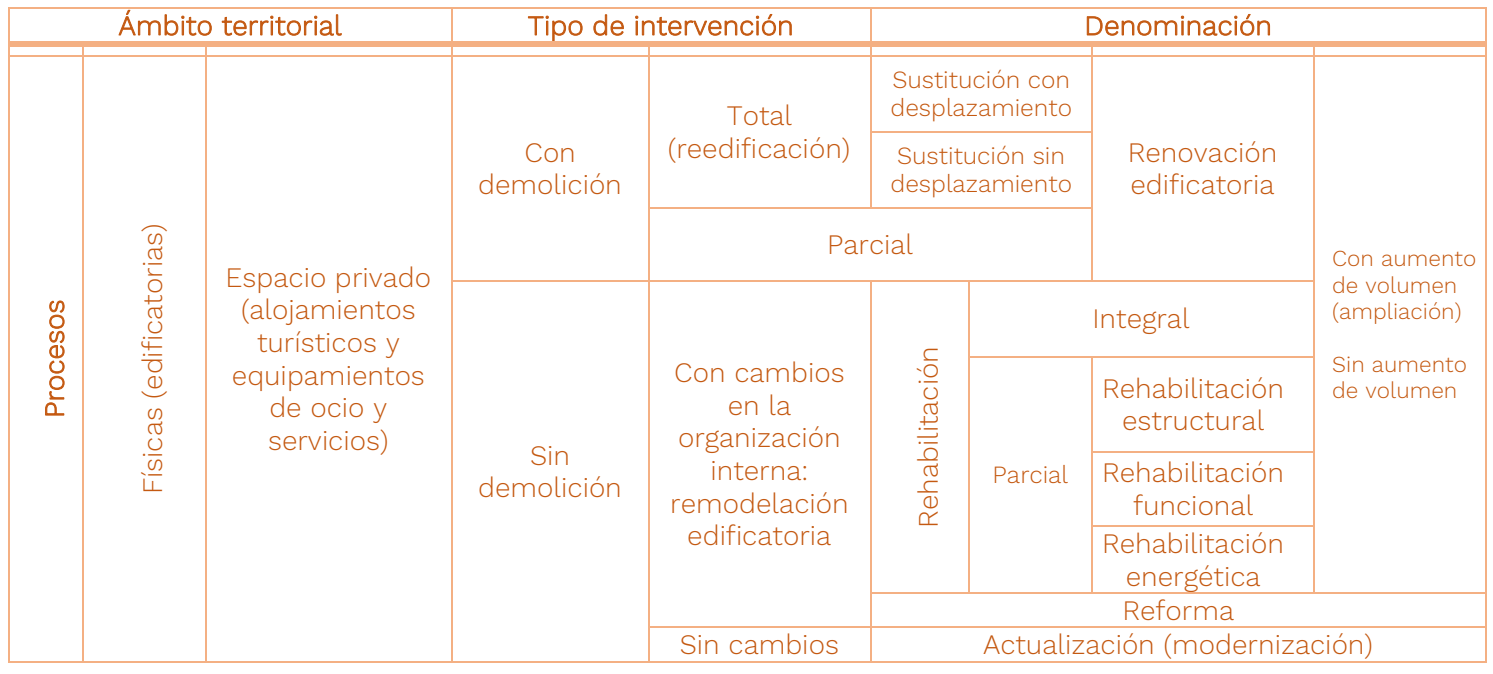

ACE, 15 (43) CC BY-ND 3.0 ES | UPC Barcelona, España | Intervenciones de regeneración en áreas turísticas de litoral. 11 Una propuesta de homogeneización terminológica. DOI: http://dx.doi.org/10.5821/ace.15.43.7037 


\begin{tabular}{|c|c|c|c|c|}
\hline & & en la & & Mantenimiento \\
\hline & & $\begin{array}{l}\text { organización } \\
\text { interna }\end{array}$ & Conservación & Reparación \\
\hline & & Reurbanización & Mejor & accesibilidad \\
\hline & & & Mejoras e & ios y dotaciones \\
\hline & Espacio público & & Mej & mbientales \\
\hline & & Remodelacion & Mejora & eatonalización \\
\hline & & & Mej & movilidad \\
\hline & & Reducción de impactos & & \\
\hline & & Integración/Cohesión/vertebra & ión territorial & \\
\hline & Territoriales & Mantenimiento y mejora de la & alidad ambienta & auración) \\
\hline & & Equilibro & & \\
\hline & & Gestión de riesgos & & \\
\hline & & Nuevos tipos de financiación & & \\
\hline & Económicas & Ayudas y subvenciones & & \\
\hline & & Nuevos modelos de negocio & & \\
\hline & & Gobernanza & & \\
\hline & Sociales & Ordenación de usos & & inación \\
\hline & & residenciales y turísticos & Segre & (zonificación) \\
\hline 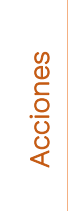 & Regeneración urbana & $\begin{array}{l}\text { Rehabilitación urbana } \\
\text { Renovación urbana }\end{array}$ & $\begin{array}{l}\text { - } R e v i t a l i z a c i \\
\text { - } R e c o n v e r s i \\
\text { - } R e c u a l i f i c a \\
\text { - } R e v a l o r i z a c \\
\text { - } R e m o d e l a c \\
\text { - } R e e s t r u c t u\end{array}$ & \\
\hline
\end{tabular}

Fuente: Moya y Díez (2012) y Simancas (2010 y 2015). Elaboración propia.

\subsection{Procesos urbanos de intervención en las áreas turísticas}

Tomando como referencia básica los antecedentes de la Estrategia de Regeneración Urbana de Castilla y León, texto que ofrece ordenadamente una referencia en las formas y prioridades de intervención en los tejidos residenciales, podemos decir que el concepto de regeneración urbana es amplio y global. Esta consideración es contraria a la planteada en el Preámbulo del 17 de enero de 2018 del Texto Consolidado del Real Decreto Legislativo 7/2015, de 30 de octubre, por el que se aprueba el texto refundido de la Ley de Suelo y Rehabilitación Urbana, donde se considera que el término "rehabilitación urbana" se engloba junto a la regeneración y renovación de los tejidos urbanos. En nuestro caso, consideramos que el término "regeneración urbana" necesariamente debe abarcar una gran variedad de enfoques de análisis y de tipos de intervención sobre la ciudad, aunque siempre con la connotación de actuar sobre algún área que, en general, ha perdido el valor que en su momento tuvo (valor ambiental, social, económico, simbólico, etc.). Se trata de intervenir sobre espacios urbanos existentes que, por el motivo que sea, se considera que no pueden continuar con su dinámica. Una primera cuestión fundamental es su escala, la cual puede ir desde la vivienda o el edificio hasta el ámbito territorial, siguiendo la tendencia de los últimos documentos de la Unión Europea al respecto, en concreto, la Carta de Leipzig y la Agenda Territorial Europea 2020. Si nos ceñimos a la escala urbana y centramos el concepto en la intervención sobre partes ya existentes de la ciudad, conviene considerar dos grandes líneas de actuación en materia de 
regeneración: la renovación, un instrumento de acción pública sobre el espacio urbano existente largamente empleado en la historia del urbanismo (García, 2017; Álvarez \& Camerin, 2019), que reestructura y transforma globalmente el espacio urbano por medio de demoliciones y reconstrucciones, y la rehabilitación, que asume las preexistencias e interviene sobre ellas, las transforma para modernizarlas, adaptándolas a las necesidades actuales o previstas en la sociedad (Robert \& Sykes, 2000). Dentro de estas dos grandes líneas, a su vez, podemos distinguir otros términos menos frecuentes, pero también utilizados para matizar o poner énfasis en un aspecto de la regeneración. Nos referimos a la revitalización, revalorización, remodelación y reestructuración urbana.

El artículo 6 de la Ley 2/2013, de 29 de mayo, de renovación y modernización turística de Canarias, define que la renovación urbana en áreas turísticas "... tendrá por objeto establecer las intervenciones públicas que resulten necesarias para inducir la regeneración de la ciudad turística conforme a un modelo sostenible y de calidad". A su vez, el Reglamento de dicha Ley (Decreto 85/2015) precisa que serán operaciones de regeneración y renovación urbanas "cuando afecten, tanto a edificios, como a tejidos urbanos, pudiendo llegar a incluir obras de nueva edificación en sustitución". Lo que parece claro en esta definición es que las operaciones de renovación urbana abarcan tanto mejoras en el espacio público como en el privado y son compatibles con la demolición, sustitución, traslado y rehabilitación de edificios, así como con la reurbanización del espacio público, no estableciéndose ninguna diferencia sustancial con las afecciones que tradicionalmente ha presentado este término en el espacio residencial.

Por otro lado, el término "rehabilitación" implica un doble reconocimiento: un cierto valor del objeto (vivienda, entorno urbano), y la inadecuación de su estado al objetivo de permanencia en el tiempo de ese valor. Por tanto, supone una perspectiva en la que el valor patrimonial está presente. Sin embargo, la rehabilitación implica transformación; no es, por tanto, sinónimo de mantenimiento (operación que tiene un carácter ordinario), ni de restauración, donde la prioridad es la permanencia de lo edificado. Dicho término ha tenido una evolución importante, desde sus primeras aplicaciones ceñidas a la preservación y conservación, a sus últimas definiciones donde queda presente su visión más integral (García, 2017). Ahora bien, lo cierto es que, en el marco legislativo vigente en Canarias, se deslinda el uso del término "rehabilitación", para centrarlo más en la edificación, utilizando en cambio los de "regeneración y renovación" para los tejidos urbanos. Así en el art.1 de la Ley 8/2013, se dice que tiene como objetivo: “... el impulso y el fomento de las actuaciones que conduzcan a la rehabilitación de los edificios y a la regeneración y renovación de los tejidos urbanos existentes, cuando sean necesarias para asegurar a los ciudadanos una adecuada calidad de vida y la efectividad de su derecho a disfrutar de una vivienda digna y adecuada".

La evolución del término "rehabilitación urbana" en el ámbito turístico ha sido similar, estando hoy también relegado. Este fue el primer término empleado en la legislación canaria para referirse a las intervenciones de mejora de los tejidos urbanos y turísticos. Sin embargo, en la actualidad, ha adoptado otro sentido, asociándose más a la mejor e implementación de infraestructuras. Prueba de ello es la denominación del Plan de Rehabilitación de las Infraestructuras Turísticas de San Agustín, Playa del Inglés y Maspalomas y el Plan para la Rehabilitación de las Infraestructuras Turísticas de Puerto de la Cruz (Rodríguez \& Such, 2014). Hemos de remontarnos a las Directrices de Ordenación General y las Directrices del Turismo de Canarias (Ley 19/2003, de 14 de abril), para encontrar una definición de rehabilitación urbana (Directriz 73): “... las zonas urbanas con destino turístico o residencial, que, teniendo o no un especial valor cultural, precisen de su rehabilitación física, social, económica y funcional, facilitando con ello la coordinación e integración de las actuaciones de las administraciones públicas afectadas". 
Como podemos comprobar, la definición dada en esta directriz es tan amplia que se torna imprecisa. La realidad es que finalmente este término ha sido abandonado, y hoy ya no aparece citado ni definido en el marco legislativo turístico de Canarias.

Tanto las intervenciones por rehabilitación como las intervenciones por renovación pueden quedar matizadas cuando se emplean los términos revitalización y revalorización. En el primer caso, con frecuencia se asocia con aquellos planes o conjuntos de intervenciones que tiene como objeto reactivar social y económicamente un sector (Beas, 2012). Por su parte, el uso del término revalorización describe de forma literal la consecuencia directa de la mejora de un ámbito sometido a operaciones de regeneración urbana, acentuando, sobre todo, el incremento del valor económico, aunque no excluyendo otro como el ambiental o social. Un buen ejemplo reciente de intervenciones en esta línea son las que emanan del Plan de Infraestructuras Turística de Canarias [PITCAN 2017-2023] (Simancas \& Peñarrubia, 2018). En conclusión, ambos términos pueden considerarse como de uso complementario en el ámbito turístico.

Los conceptos "remodelación" y "restructuración urbana" suponen expresiones mucho más marginales no localizadas en la legislación estatal en materia de vivienda y en el marco jurídico canario en materia de turismo. Ambos términos son sinónimos. Tratan de describir la sustitución de la edificación, atendiendo a una nueva ordenación urbanística (Cervero y Hernández, 2015), completando la definición con la sustitución también del trazado viario, así como su reparcelación, reurbanización y construcción posterior de nuevas edificaciones (Moya y Díez, 2012).

\subsection{Acciones físicas}

\subsubsection{Intervenciones en los espacios públicos de las áreas turísticas consolidadas}

De manera general, las acciones físicas sobre el espacio urbano-turístico pueden dividirse en dos ámbitos de naturaleza distinta, pero complementarias: el espacio público y el espacio privado. La importancia de los espacios públicos de las áreas turísticas radica, entre otras cuestiones, en que resulta ser el espacio de convivencia de los turistas y los residentes; además, es soporte de las circulaciones y referencia del paisaje urbano, determinado en última instancia, por la propia parcelación y los sistemas de ordenación utilizados en cada caso. Por su parte, el espacio privado, formado por la edificación, se identifica tanto con las distintas tipologías de alojamiento existentes en el área (apartamentos, hoteles, villas, etc.), como por equipamientos de servicios de ocio. La combinación entre el espacio público y el privado da como resultado las diferentes morfologías urbanas que se pueden distinguir en la ciudad. Las intervenciones en los destinos turísticos suelen acoger intervenciones en ambos espacios.

La intervención en el espacio público le corresponde a la administración pública. Su actuación expresa el interés y compromiso por revertir la situación de pérdida de competitividad del destino. En ocasiones, estas actuaciones se priorizan y sirven de catalizadores para precipitar posteriormente mejoras por parte de la iniciativa privada. También hay casos en los que es la iniciativa privada con su inversión en el espacio parcelado la que impulsa la regeneración urbana, para luego ser la administración quien complementa o secunda la actuación con medidas de mejora en lo público.

Los términos que de forma más habitual se emplean en las actuaciones físicas sobre el espacio público son los de reurbanización y remodelación de la urbanización.

Según señala el anterior Plan Estatal de Vivienda 2013-16, cuando se alude a la reurbanización, se refiere a obras de pavimentación, jardinería, infraestructuras, instalaciones, servicios de 
abastecimiento de agua, saneamiento, suministro energético, alumbrado, recogida, separación y gestión de residuos, telecomunicaciones y utilización del subsuelo. En estas también se incorporan las de mejora de la accesibilidad de los espacios públicos y las destinadas a mejorar la eficiencia ambiental en materia de agua, energía, uso de materiales, gestión de residuos y protección de la biodiversidad. Sin embargo, la legislación canaria en materia del turismo no recoge este término en ningún caso, aunque se emplean expresiones como "mejora de la urbanización" o "renovación de la urbanización”, para aludir al significado resumido en el término "reurbanización”, que podemos dar, por tanto, como de uso común.

Por otro lado, el término "remodelación de la urbanización" tampoco queda recogido en la legislación canaria para la mejora de los espacios turísticos, si bien dentro de los Planes de Modernización, Mejora e Incremento de la Competitividad contempla intervenciones bajo esta denominación o se alude a ella de manera indirecta cuando se señala que "...las intervenciones o actuaciones públicas en el espacio urbano o, en general en el núcleo o en la zona turística, que coadyuven a su recualificación y mejora", entre las que se cita las de: "resolver los problemas de congestión en materia de accesibilidad y movilidad viaria, ampliar la oferta de aparcamientos en las áreas infradotadas y establecer medidas para la gestión eficaz de la red de aparcamientos, mejorar la red peatonal y el uso de vehículos no motorizados, y recuperar e incrementar en su caso el acceso público a las playas y el mar".

\subsubsection{Intervenciones en los espacios privados de las áreas turísticas consolidadas}

Los espacios privados, conformados por los establecimientos de alojamiento turístico y los equipamientos de ocio, constituyen verdaderos "activos" de las áreas turísticas de litoral (Simancas, Dorta y Dávila, 2017). Ello se debe a que constituyen activos estructurales de los mismos desde una doble funcionalidad: por un lado, como lugares de pernoctación desde el que visitar el destino y, por tanto, como complemento de los recursos (naturales, culturales, etc.); por otro, como recursos focales, al ser el principal motivo del viaje y de atracción, hasta el punto que el uso y disfrute de sus equipamientos y servicios articulan la experiencia turística, llegando, incluso, a ser el escenario donde se desarrolla prácticamente la totalidad de la estancia; en estos casos, los alojamientos turísticos se convierten en los destinos. Por ello, su renovación constituye una estrategia clave de cualquier política de reposicionamiento competitivo de las áreas turísticas maduras (Simancas, 2015). Resulta de gran interés la distinción que se hace en el artículo 2 del Decreto 138/2010, de 23 de septiembre, por el que se desarrolla la previsión en materia de rehabilitación de establecimientos turísticos contenida en la Ley 6/2009, de un establecimiento de alojamiento "deteriorado" y "obsoleto". La primera definición alude a aquel en el que se produce una falta de conservación, un menoscabo y un quebranto que presentan los elementos estructurales y accesorios del edificio, las instalaciones o dotaciones técnicas y el equipamiento turístico complementario, de ocio, salud o deportivas del mismo. En cambio, la situación de obsolescencia física se refiere a aquella que se produce por un grado de inadecuación de la funcionalidad, la seguridad, la habitabilidad o calidad ambiental del edificio, del equipamiento turístico complementario de ocio, salud, deportivas o de esparcimiento o de las instalaciones técnicas, a la ordenación turística vigente o, en general, a la normativa que fuera de aplicación. Lo mismo sucede en otras situaciones de obsolescencia del establecimiento turístico (estética, funcional, de modelo de negocio, de modelo organizativo, formas de segmentación, canales de comercialización, etc.). Ambas situaciones son consecuencia de procesos de old-fashioned (pasado o fuera de moda) (Simancas, 2011), que se generan cuando la estructura física, la funcionalidad de las instalaciones y servicios o la propia gestión operativa resultan insuficientes o son superadas por las tendencias de la demanda y los nuevos patrones de comportamiento de los turistas. Ambas situaciones producen externalidades negativas sobre el resto del sector y el área turística (Simancas, 2016).

ACE, 15 (43) CC BY-ND 3.0 ES | UPC Barcelona, España | Intervenciones de regeneración en áreas turísticas de litoral.

Una propuesta de homogeneización terminológica. DOI: http://dx.doi.org/10.5821/ace.15.43.7037 
Sin embargo, las intervenciones en los alojamientos turísticos y en los equipamientos de ocio y servicios no solo deben corregir ambas situaciones. También deben permiten integrar innovaciones, soluciones técnicas actualizadas y obligaciones normativas relacionadas con la sostenibilidad ambiental, tales como el uso eficiente de energías, los consumos de agua y la incorporación de soluciones arquitectónicas bioclimáticas en los equipamientos, cuestiones cada vez más apreciadas por los clientes (Simancas, 2010). Asimismo, en la medida en que, en la actualidad, el éxito competitivo de cualquier destino turístico depende, entre otros factores, de su diferenciación, segmentación y diversificación, la seguridad, la conectividad, la prestación de servicios de calidad, así como la disponibilidad de unas infraestructuras y equipamientos innovadores y de prestigio, tales intervenciones deben posibilitar tales acciones. Del mismo modo, deben incidir sobre los principales indicadores del negocio turístico y de la rentabilidad empresarial (número de pernoctaciones, estancia media, índices de ocupación, Average Daily Rate, Revenue Per Available Room, Gross Operating Profit Per Available Room, etc.). Por consiguiente, las intervenciones en los alojamientos turísticos y equipamientos de ocio y servicios no solo deben ser físicas ("sobre el hadware”), sino también funcionales (“sobre el software”) (Simancas y Hernández, 2015).

A continuación, pasaremos a definir las distintas acepciones empeladas para intervenir físicamente en la edificación, desde las más superficiales y básicas hasta las más intrusivas. Su aplicación a las áreas turísticas ha sido abordada, entre otros, por Yepes (1996), Chinchilla (2009), Simancas (2010 y 2011) y Dorta (2015).

\section{- Conservación edificatoria}

El artículo 43 de la Ley 7/1995, de Ordenación del Turismo de Canarias, establece que los establecimientos de alojamiento turístico deberán mantenerse en las adecuadas condiciones de ornato y de funcionalidad requeridas por el uso a que se destinan y, al menos, con la calidad que fue tenida en cuenta en el momento de su clasificación. Asimismo, el artículo 44 eleva el deber de la renovación a una obligación; así, para poder conservar la clasificación que posean, deben poner en práctica un programa especial de mantenimiento destinado a la incorporación de soluciones técnicas actualizadas.

Estas operaciones habituales de mantenimiento, ornato y reparación en la edificación, encaminadas al buen funcionamiento de las instalaciones y servicios, estarían agrupadas en las conocidas como operaciones de conservación del edificio. Estas repercuten en dos ámbitos claramente diferenciados: el relativo al valor patrimonial del edificio y el relativo a las operaciones habituales dirigidas a su mantenimiento y reparación.

En relación con el primero, la "conservación" se define en la Carta de Cracovia de 2000 como el "conjunto de actitudes de una comunidad dirigidas a hacer que el patrimonio y sus monumentos perduren". Si bien pudiera parecer inicialmente que esta reflexión no constituye una discusión presente en los ámbitos turísticos litorales, muy por el contrario, cada vez más se hacen más reconocibles valores patrimoniales en las arquitecturas o en los trazados urbanos de muchos de los destinos vacacionales.

Por su parte, en la acepción del término más vinculado a las labores habituales de mantenimiento y reparación, el deber de conservación aparece nítidamente definido en la primera Ley de Suelo española del año 1956, cuyo artículo 186 establecía que "los propietarios de terrenos, urbanizaciones particulares, edificaciones y carteles, deberán mantenerlos en condiciones de seguridad, salubridad y ornato públicos". Este ha estado presente en todas las leyes del suelo, ampliándose y añadiéndose nuevos contenidos (Sospedra, 2013) en las sucesivas normas del suelo. Los ámbitos turísticos no quedan exceptuados del cumplimiento de los mismos principios.

ACE, 15 (43) CC BY-ND 3.0 ES | UPC Barcelona, España | Intervenciones de regeneración en áreas turísticas de litoral. 16 Una propuesta de homogeneización terminológica. DOI: http://dx.doi.org/10.5821/ace.15.43.7037 
Si bien este deber aparece citado en múltiples regulaciones de carácter estatal, autonómico, sectorial y local, con acepciones similares, destacamos la contenida en la Ley 8/2013, de 26 de junio, de rehabilitación, regeneración y renovación urbanas, donde se define las obras de reparación y/o de estricto mantenimiento como: "el conjunto de trabajos y obras a efectuar periódicamente para prevenir el deterioro de un edificio o reparaciones puntuales que se realicen en el mismo, con el objeto mantenerlo en buen estado para que, con una fiabilidad adecuada, cumpla con los requisitos básicos de la edificación establecidos".

Por tanto, comprende tres modalidades básicas del deber de conservación:

a) Las condiciones legales de uso: mantener la edificación o demás elementos (terrenos, instalaciones o construcciones en condiciones legales, adaptándolos si fuese necesario, para servir de soporte al uso que corresponda.

b) El deber ordinario de conservación: mantener los inmuebles en condiciones de seguridad, salubridad, accesibilidad universal y ornato legalmente exigibles.

c) Las medidas adicionales de conservación: Realizar obras adicionales por motivos turísticos, culturales o para la mejora de la calidad y sostenibilidad del medio urbano.

\section{- Rehabilitación}

Las primeras referencias a la "rehabilitación" en contextos normativos se remontan a los primeros ayuntamientos democráticos, con el surgimiento de lo que en la disciplina urbanística tradicionalmente se ha conocido como la generación de planes orientados a la "recuperación de la ciudad". Con el Real Decreto Ley 12/1980, de 26 septiembre, y su instrumento de desarrollo, el Real Decreto 375/ 1982 de 12 de febrero, la rehabilitación se entiende como una combinación de mejoras, sustituciones, cambios de instalaciones, incrementos de la seguridad, refuerzos estructurales, ahorros energéticos y consolidación, pero se limita a viviendas o a edificios declarados monumentos histórico-artísticos o que formen parte de conjuntos histórico-artísticos. Por tanto, la condición de valor patrimonial acompaña inicialmente a la acción rehabilitadora.

Dicha condición despareció a partir del Real Decreto 726/1993, de 14 de mayo, por el que se regula la financiación de actuaciones protegibles en materia de rehabilitación de inmuebles y se modifican determinados artículos del Real Decreto 1932/1991, de 20 de diciembre. La definición más completa que encontramos en la legislación la tenemos que buscar en el Real Decreto 314/2006, de 17 de marzo, por el que se aprueba el Código Técnico de la Edificación. En la redacción original de los epígrafes 4 y 5 del apartado 2 (derogados) se hacía una distinción entre lo que podría entenderse como rehabilitación parcial, frente a la rehabilitación integral. Así para la rehabilitación parcial define las siguientes categorías: "Rehabilitación a través de la adecuación estructural: Obras que proporcionen al edificio condiciones de seguridad constructiva, de forma que quede garantizada su estabilidad y resistencia mecánica, Rehabilitación a través de la adecuación funcional: La realización de las obras que proporcionen al edificio mejores condiciones respecto de los requisitos básicos a los que se refiere este CTE. Se consideran, en todo caso, obras para la adecuación funcional de los edificios, las actuaciones que tengan por finalidad la supresión de barreras y la promoción de la accesibilidad, de conformidad con la normativa vigente, y Rehabilitación a través de la remodelación: La modificación de la superficie destinada a vivienda o modificar el número de éstas, o la remodelación de un edificio sin viviendas que tenga por finalidad crearlas".

A estas categorías de rehabilitación parcial habría que añadir la denominada rehabilitación energética, pues es una constante en la demanda de rehabilitación apuntada con posterioridad en la mayor parte de los marcos normativos que inciden sobre la edificación existente. Se entiende por

ACE, 15 (43) CC BY-ND 3.0 ES | UPC Barcelona, España | Intervenciones de regeneración en áreas turísticas de litoral. 17 Una propuesta de homogeneización terminológica. DOI: http://dx.doi.org/10.5821/ace.15.43.7037 
"rehabilitación energética" el conjunto de medidas que se adopten para mejorar la eficiencia energética o reducir el consumo energético del edificio, sea a través del uso de energías renovables o mediante la mejora del rendimiento energético.

Por su parte, siguiendo las definiciones del Decreto 314/2006, cuando nos referimos a una acción de rehabilitación integral, hablamos de aquella que integre todas las acciones anteriores, no necesariamente con la misma profundidad.

Por otra parte, el uso generalizado del término "rehabilitación" en la normativa y el lenguaje técnico es tal que su ausencia, en determinados casos, ha llegado a motivar la denegación de subvenciones dirigidas a determinadas operaciones de renovación. Por este motivo, hemos optado por emplearlo en esta propuesta de homogeneización terminológica, aun cuando, en realidad, hace referencia a operaciones de renovación. En efecto, en la práctica, éstas aluden a actuaciones de "reciclaje" de los alojamientos turísticos y los equipamientos de ocio y servicios y, por tanto, un aprovechamiento del valor de la oferta turística existente. Ello se debe a que no se limitan a reformas dirigidas a lograr el mero cumplimiento de las normas turísticas vigentes o acciones de restitución de los mismos a su estado original, a través de actuaciones mantenimiento y conservación. Por el contrario, aprovechando los elementos estructurales y accesorios del edificio, las actuaciones implican, como mínimo, la modernización estética (ornato) y, sobre todo, la actualización y mejora de las unidades de alojamiento y de los espacios comunes, de modo que, si bien se mantienen las características tipológicas y funcionales básicas del inmueble, se aborda una modificación en profundidad de los elementos menos duraderos (instalaciones, pavimentos, acabados, carpinterías interiores y exteriores, sanitarios y otros), las máximas implican un cambio estructural del inmueble, incluyendo la reducción del número de unidades de alojamiento y, por ende, de plazas turísticas. Por tanto, comprende las operaciones que, interviniendo, total o parcialmente, sobre lo ya construido, deben producir a medio y largo plazo tanto un efecto tangible e inmediato en la propia apreciación del cliente, así como un impacto positivo en la competitividad del establecimiento de alojamiento -e incluso, en la zona donde se ubica-, entendido como una mejora (en términos de beneficios y/o la cuota de mercado) de los resultados (indicadores). En este último caso, la rehabilitación, entendida como renovación, supone un intento de "reinventar" el producto turístico del establecimiento de alojamiento turístico, de modo que las reformas permiten la incorporación de nuevos conceptos e ideas no sólo en términos estrictamente edificatorios (físicos), sino también en cuestiones relacionadas con la implementación de un nuevo modelo de negocio.

De forma residual a las defunciones anteriores, en ocasiones se emplea el término "remodelación" para hacer referencia a cambios o adecuaciones funcionales, estructurales o superficiales de menor intensidad que una rehabilitación. En la legislación canaria en materia de turismo no se emplea dicho término y en la nacional en materia de vivienda se empleó en los Planes nacionales de viviendas 1998-2001; 2002-2005 y 2005-2008.

\section{- Sustitución}

La sustitución de una obra implica la previa demolición, que puede ser parcial o total, con objeto de adaptar un edificio preexistente a las nuevas necesidades funcionales y estéticas, pudiendo implicar cambios de volumetría y superficies construidas. En el contexto turístico, la sustitución como estrategia de reequilibrio ha sido planteada desde al menos hace 15 años. La Ley 13/2003 de Directrices, así como la Ley 2/2013 inciden en que por sustitución se entiende la demolición del edificio existente, para construir uno totalmente nuevo. La idea de intervenir por sustitución (demolición) en el marco normativo canario ha estado siempre vinculada a la de traslado (total o parcial) de la capacidad de alojamiento turístico y de equipamientos turísticos complementarios hacia un nuevo emplazamiento diferente al original en la misma área turística no consolidada o en

ACE, 15 (43) CC BY-ND 3.0 ES | UPC Barcelona, España | Intervenciones de regeneración en áreas turísticas de litoral. 
otro municipio de la isla, ofreciendo incentivos como estrategia para lograr un nuevo equilibrio en la distribución de los usos y densidades en las áreas turísticas. De esta manera, se trata de una operación de "reutilización" de la parcela cuando la construcción del nuevo establecimiento se realiza en la misma parcela.

En la actualidad, se sigue recogiendo en la Ley 2/2013 y en el Decreto 85/2013, de 14 de mayo, por el que se aprueba su Reglamento, de forma que se entiende como una operación que aporta ventajas tanto para las áreas turísticas emisoras como para las receptoras. Para las primeras posibilita la disminución de la densidad edificatoria y la reducción del número de plazas turísticas, la eliminación de alojamientos turísticos obsoletos y/o antiguos, la especialización de usos (residenciales o turísticos), así como la obtención de suelo susceptible de destinarse, bien a la corrección del déficit existente de equipamientos complementarios, bien a la generación de nuevos espacios libres y dotacionales públicos (plazas, zonas verdes, equipamientos colectivos, etc.) a través de operaciones de esponjamiento. Para las segundas abre la posibilidad de construir nuevas plazas de alojamiento turístico acordes con los estándares urbanísticos vigentes a la vez que permite incorporar las nuevas tendencias en relación con los productos turísticos.

\section{Conclusiones}

Uno de los problemas que hemos querido poner de relieve en este trabajo, utilizando el caso de Canarias, es que los procesos de regeneración de las áreas turísticas de litoral tienen que enfrentarse previamente a la ambigüedad terminológica propia del marco jurídico de referencia. Ello dificulta sobremanera el debate sobre las formas de abordar la intervención. Así, la propuesta terminológica planteada en este trabajo clasifica las acciones y procesos de aplicación sobre el destino turístico (a diferente escala) y la estructura del área turística o sobre partes concretas (establecimientos turísticos de alojamiento, infraestructuras y equipamientos) según su alcance, intensidad y capacidad de transformación.

Hablar de reformas, cambios y aumento de calidad en destinos turísticos consolidados, implica, no solamente una actuación física en las infraestructuras que dan soporte al alojamiento y la oferta complementaria. Hemos de entender la verdadera amplitud de la propuesta de actualización adoptando una perspectiva integral en la que al menos quedan implicadas una visión que comprende lo físico, lo territorial, lo económico y lo social.

Por otra parte, para el ámbito turístico, dichos términos han venido, en su mayoría, heredados de las intervenciones propuestas en los últimos años para la ciudad residencial. La obsolescencia avanzada que muestran buena parte de las periferias de nuestras ciudades, construidas predominantemente en la década de los setenta y setenta, ha producido un giro en las atenciones prioritarias del urbanismo de cara a los próximos años. En parte, la coincidencia de fecha de formación de muchos destinos turísticos, ha marcado un camino paralelo en ambas actividades, dirigidas a lograr una actualización de las condiciones necesarias para el desarrollo de las actividades. Esta transición de términos entre el ámbito residencial y el turístico, ha contribuido en parte a trasladar contextos y problemáticas que no son afines ni compartidas entre la actividad turística y la residencial, contribuyendo con ello a aumentar la imprecisión.

Finalmente, esta falta de discusión o debate terminológico se debe, en gran medida, al abandono de la visión territorial como marco adecuado de discusión de la mejora en los espacios turísticos. No debemos olvidar que el turismo es una actividad que usa el territorio como soporte y como recurso, por lo que una discusión sin tener encuentra las variables territoriales lleva 
inevitablemente a la esterilidad, en coherencia con lo indicado por Pié (2014: 37), "el futuro del turismo se juega en el reconocimiento del lugar y en la capacidad de explotar lo que le distingue".

\section{Agradecimientos}

La investigación que da lugar a este trabajo constituye uno de los resultados del proyecto "Análisis de la sostenibilidad urbana como estrategia de regeneración del espacio público de las áreas turísticas de litoral” (2017REC17), financiado por la Fundación CajaCanarias. Asimismo, se inscribe en el proyecto Overtourism\&Degrowth "Overtourism in Spanish Coastal Destinations. Tourism Degrowth Strategies" (RTI2018-094844-B-C31), financiado por el Ministerio de Ciencia, Innovación y Universidades.

Este texto toma como referencia el trabajo: SIMANCAS, M. TEMES, R. Y DÁVILA, H. (2016): Intervenciones urbanas y edificatorias en clave de re: una propuesta de homogenización de términos usados en los procesos de regeneración de las áreas turísticas de litoral, presentada en el XIX Congreso de la Asociación Española de Expertos Científicos en Turismo.

\section{Autoría}

El primer autor planteó el diseño de la investigación, sistematizó los conceptos utilizados en la normativa canaria de renovación turística y en la bibliografía referida a este ámbito territorial, participó en la discusión de la propuesta de homogeneización terminológica, así como escribió parte del trabajo. El segundo autor sistematizó los términos relativos a la renovación de los espacios urbanos, participó en la discusión de la propuesta de homogeneización terminológica y escribió parte del trabajo. Y la tercera autora realizó la revisión sistemática de la literatura y participó en la discusión de la propuesta de homogeneización terminológica.

Conflicto de intereses: Los autores declaran que no hay conflicto de intereses.

\section{Bibliografía}

Agarwal, S. (1997). The resort cycle and seaside tourism: an assessment of its applicability and validity. En: Tourism Management, 18(2), 65-73. DOI: http://dx.doi.org/10.1016/s0261-5177(96)00102-1

Agarwal, S. (2002). Restructuring seaside tourism. The resort lifecyle, Annals of Tourism Research, 29(1), 25-55. DOI: http://dx.doi.org/10.1016/S0160-7383(01)00002-0

Aguiló, E. y Alegre, J. (2004). La madurez de los destinos turísticos de sol y playa. El caso de las Islas Baleares. Papeles de Economía Española, 102: 250-270.

Aguiló, E.; Alegre, J. y SAMPOL, J. (2002). El futuro de los destinos turísticos maduros: ¿mantenimiento o declive? En L. Valdés; V. Monfort; J. Pulido y E. Del Valle (coord.): VI Congreso AECIT. Nuevas tendencias de ocio y turismo: su especial problemática en destinos singulares (pp. 317-328). España, Asociación Española de Expertos Científicos en Turismo.

Álvarez, A y Camerin, F. (2019). La herencia del urban renewal en los procesos de regeneración urbana: el recorrido Renovación-Regeneración a debate. Ciudad y Territorio. Estudios territoriales, 51 (199), 5-26. 
Antón, S. (1998). La urbanización turística. De la conquista del viaje a la reestructuración de la ciudad turística. Documentos d'Anàlisi Geográfica, 32, 17-43.

Antón, S. (2005). De los procesos de diversificación y cualificación a los productos turísticos emergentes. Cambios y oportunidades en la dinámica reciente del turismo litoral. Papeles de Economía Española, 102, 316-333.

Antón, S. (2011). Dinámicas de reestructuración de los destinos turísticos litorales del Mediterráneo. Perspectivas y condicionantes. En D. LóPEz (ed.): Renovación de destinos turísticos consolidados (pp. 23-40). Valencia, España, Tirant Lo Blanch.

Antón, S., Fernández, A. y González, F. (2008): Los lugares turísticos. En S. Antón y González, f. (coords.): A propósito del turismo. La construcción social del espacio turístico (pp. 103-206). Universitat Oberta de Catalunya.

Barrado, D. (2004). El concepto de destino turístico. Una aproximación geográfico-territorial. Estudios Turísticos, 160, 45-68.

Baum, T. (1998). Taking the exit route: extending the tourism area life cycle model. Current Issues in Tourism, 1, 167-175.

Beas, L. (2012). Los planes de excelencia turística en España (1992-2006). Una apuesta por la revitalización de los destinos. Revisión de su implantación e impactos. Scripta Nova: revista electrónica de Geografía y Ciencias Sociales, 16.

Beritelli, P., Bieger, T. y Laesser, C. (2014). The new frontiers of Destination management. Journal of Travel Research, 53(4), 403-417.

Blanco, R. (2012). Planificación de destinos turísticos maduros. Consideraciones para su reconversión. En F. VERA y I. RODRIGUEZ (Eds.): Renovación y restructuración de destinos en áreas costeras. Marco de análisis, procesos, instrumentos y realidades (pp. 55-68). Valencia, España, Universitat de València.

Butler, R. (1980). The concept of a tourism area cycle of evolution: Implications for the management of resources. Canadian Geographer, 24(1), 5-12. DOI: http://dx.doi.org/10.1111/j.15410064.1980.tb00970.x

Butler, R. (2012): Mature Tourist Destinations: can we recapture and retain the magic? En F. Vera y I. Rodríguez (eds.): Renovación y restructuración de destinos en áreas costeras. Marco de análisis, procesos, instrumentos y realidades (pp. 19-36). Valencia, España, Universitat de València.

Camisón, C. y Monfort, V. (1998). Estrategias de reposicionamiento para destinos turísticos maduros: el caso de la Costa Blanca. Estudios turísticos, 135, 5-28.

Castrillo, M., Matesanz, A., Sánchez, D. y Sevilla, A. (2014). ¿Regeneración urbana? Deconstrucción y reconstrucción de un concepto incuestionado. Papeles de relaciones ecosociales y cambio global, 126, 129-39.

Celdrán, M., Mazón, J., Ivars, J. y Vera, F. (2018). Smart tourism. Un estudio de mapeo sistemático. Cuadernos de Turismo, 41. DOI: http://dx.doi.org/10.6018/turismo.41.326971

Cervero, N. y Hernández, L. (2015). Remodelación, Transformación y Rehabilitación. Tres formas de intervenir en la vivienda social del siglo XX. Informes de la Construcción, 67 (Extra-1). DOI: http://dx.doi.org/10.3989/ic.14.049 
Chapman, A. y Light, D. (2016). Exploring the tourist destination as a mosaic: The alternative lifecycles of the seaside amusement arcade sector in Britain. Tourism Management, 52, 254-263.

Chinchilla, J. (2009). La rehabilitación de los establecimientos turísticos alojativos como manifestación del desarrollo urbanístico sostenible. El ejemplo de Canarias. Práctica urbanística. Revista mensual de urbanismo, 87, 64-77.

Donaire, J.A. y Mundet, Ll. (2001). Estrategias de reconversión turística de los municipios litorales catalanes. Papers de Turisme, 29, 50-66.

Dorta, A. (2015). Análisis del proceso de renovación de la oferta turística de alojamiento en destinos consolidados: el caso de Puerto de la Cruz (Tenerife). (Tesis doctoral). Universidad de La Laguna. San Cristóbal de La Laguna.

Exceltur (2003). Hacia un nuevo paradigma en el modelo de gestión de los destinos del litoral mediterráneo y las islas: Los Proyectos de Reconversión Integral de Destinos Turísticos (PRIDET). Madrid, España: Área de Estudios e Investigaciones de Exceltur.

Falcón, C. (2019). Valorando políticas públicas de renovación en áreas turísticas maduras. Revista Aragonesa de Administración Pública, 53, 344-383.

Gaja, F. (2015): La regeneración urbana en la encrucijada. ACE: Architecture, city and Environment, 9(27), 11-26. DOI: http://dx.doi.org/10.5821/ace.9.27.2803

Garcia, A. (2009). Modernización de destinos turísticos maduros: regulación. La administración práctica: enciclopedia de administración municipal, 3, 267-270.

García, S. (2017). Diseño urbano y espacio público en contextos de regeneración urbana integrada: conceptos, marco institucional y experiencias recientes. ZARCH: Journal of interdisciplinary studies in Architecture and Urbanism, (8), 214-227.

Getz, D. (1992). Tourism planning and destination life cycle. Annals of Tourism Research, 19(4), 752770. DOI: http://dx.doi.org/10.1016/0160-7383(92)90065-W

González, F. (2012). El modelo de reestructuración turística de la Costa Daurada. En F. Vera y I. Rodríguez (Eds.), Renovación y restructuración de destinos en áreas costeras. Marco de análisis, procesos, instrumentos y realidades (pp. 219-241). Valencia, España: Universitat de València.

Granda, J.; Alonso, A.; García, F.; Solano, S.; Jiménez, C.; Aleixandre, R. (2013). Ciertas ventajas de Scopus sobre Web of Science en un análisis bibliométrico sobre tabaquismo. Revista española de Documentación Científica, 36 (2): e011, DOI: http://dx.doi.org/10.3989/redc.2013.2.941

Ivars, J. (2003). Planificación turística de los espacios regionales en España. Madrid, España: Síntesis. Ivars, J., Rodríguez, I y Vera, F. (2013). The Evolution of Mass Tourism Destinations: New Approaches Beyond Deterministic Models in Benidorm (Spain). Tourism Management, 34, 184-195. DOI: http://dx.doi.org/10.1016/j.tourman.2012.04.009

Ivars, J., Rodríguez, I., y Vera, F. (2013). The evolution of mass tourism destinations: New approaches beyond deterministic models in Benidorm (Spain). Tourism Management, 34, 184-195. DOI: http://dx.doi.org/10.1016/j.tourman.2012.04.009

Knowles, T. y Curtis, S. (1999). The market viability of European mass tourist destinations. A PostStagnation Life-Cycle Analysis. International Journal of Tourism Research, 1, 4, 87-96.

Llorca, E. y Sosa, A. (2010). Procesos de reciclaje aplicados al turismo de masas en el Sur de Gran Canaria. En Congreso Internacional Sustainable Building. 
Mansfield, J. (2002). What's in a name? Complexities in the definition of "refurbishment". Property Management, 20 (1), 23-30.

Medina, D., Medina, R., Sánchez, A. (2016). Renovation strategies for accommodation at mature destinations: A tourist demand-based approach. International Journal of Hospitality Management, 54, 127-138

Mirallave, V. (2004). Consideraciones sobre la renovación del espacio turístico canario. Cartas urbanas, 9, 84-93.

Moya, L. y Díez, o. (2012). La intervención en la ciudad construida: acepciones terminológicas. Urban, 4, 13-123.

Mullins, P. (1994). Class Relations and Tourism Urbanization: The Regeneration of the Petite Bourgeoisie and the Emergence of a New Urban Form. International Journal of Urban and Regional Research, 18, 4, 591-608.

Navarro, E. (2006). Proceso de crecimiento e intensificación de usos en los destinos turísticos consolidados. En LACOSTA S, (Coord.), Turismo y cambio territorial: ¿eclosión, aceleración, desbordamiento? IX Coloquio de Geografía del Turismo, Ocio y Recreación (pp. 319-350). Zaragoza, España: Asociación de Geógrafos Españoles.

Oreja, J. (2000). Revitalización de destinos turísticos maduros. En D. BLANQuer (Coord.), Turismo: comercialización de productos, gestión de organizaciones, aeropuertos y protección de la naturaleza (pp. 199-232). Valencia, España: Tirant lo Blanch.

Perelli, O. y Prats, F. (2007). La apuesta por la reconversión de los destinos maduros del litoral. Estudios Turísticos, 172-173, 203-212.

Pié, R. y Rosa, C. (Eds.) (2014). Turismo líquido. Barcelona, España, Ed UPC.

Priestley, G. y Mundet, LL. (1998). The post-stagnation phase of the resort cycle. Annals of Tourism Research, 25, 85-111, DOI: http://dx.doi.org/10.1016/S0160-7383(97)00062

Roberts, P. y Sykes, H. (2000). Urban Regeneration. A Handbook. London, England: Thousand Oaks, Calif. SAGE Publications Ltd.

Rodríguez, I., y Such, M. (2014): La política turística española de apoyo a la renovación y reestructuración de destinos turísticos maduros: una valoración a partir de las experiencias piloto recientes. ACE-Arquitectura, Ciudad y Entorno, 9, 437-466.

Rodríguez, M. y Rodríguez, R. (2018). A Decision-Making and Governance Framework for the Renewal of Tourism Destinations: The Case of the Canary Islands. Sustainability, 10(2), 310.

Rodríguez, P. y Santana, M. (2013). La reconversión hotelera en las regiones turísticas españolas. Rasgos y efectos generales. En XI Congreso Español de Sociología. Madrid, España: Universidad Complutense de Madrid.

Rubio Del Val, J. (2011). Rehabilitación Urbana en España (1989-2010). Barreras actuales y sugerencias para su eliminación. Informes de la Construcción, 63, Número Extra, 5-20.

Rullán, O. (2008). Reconversión y crecimiento de las zonas turísticas: del fordismo al postfordismo. En Troitiño, M. A, García E, y García, Mā (Coord.): Destinos turísticos: viejos problemas, ¿nuevas soluciones?, X Coloquio de Geografía del Turismo, Ocio y Recreación (pp. 587-626), Cuenca, España: Universidad de Castilla-La Mancha. 
Santos, E. y Fernández, A. (2010). El litoral turístico español en la encrucijada: entre la renovación y el continuismo. Cuadernos de Turismo, 25, 185-206.

Simancas, M. (2010). La renovación edificatoria de la oferta turística de alojamiento en destinos consolidados: la experiencia de Canarias. Revista de Geografía de la Universitat de Valencia, 87, 2344.

Simancas, M. (2011). El fracaso de la renovación de áreas turísticas consolidadas de litoral a través de la sustitución de la oferta alojativa obsoleta: la experiencia de las Islas Canarias. Cuadernos de Turismo, 27, 869-899.

Simancas, M. (2012). Evaluando políticas públicas de renovación de destinos turísticos maduros: el proceso de reconversión turística de Canarias. En F. VERA y I. RODRíGUEZ (Eds.): Renovación y restructuración de destinos en áreas costeras. Marco de análisis, procesos, instrumentos y realidades (pp: 163-200). Valencia, España: Universitat de València.

Simancas, M. (2015). La moratoria turística de Canarias. La reconversión de un destino maduro desde la Ordenación del Territorio. San Cristóbal de La Laguna, España: Servicio de Publicaciones de la Universidad de La Laguna.

Simancas, M. (2016). La política canaria de renovación de las áreas turísticas del litoral. En M. Simancas y E. Parra (coords.): ¿Existe un modelo turístico canario? (pp. 107-144). San Cristóbal de La Laguna, España: Promotur Turismo Canarias, S.A. / Vicerrectorado de Relaciones con la Sociedad de la Universidad de La Laguna.

Simancas, M. y Hernández, R. (coord.) (2015). Reinventando alojamientos turísticos. Casos de éxito y soluciones innovadoras. San Cristóbal de La Laguna, España: Cátedra de Turismo Caja CanariasAshotel de la Universidad de La Laguna.

Simancas, M. y Peñarrubia, M. P. (coords.) (2018). El Plan de Infraestructuras Turísticas de Canarias [PITCAN 2017-2023]. Las Palmas de Gran Canaria, España: Consejería de Turismo, Cultura y Deportes del Gobierno de Canarias / Promedia Exclusivas Publicitarias.

Simancas, M., De Souza, A. y Núñez, M. (2010). La renovación de los espacios públicos de las áreas turísticas consolidadas. En R. Hernández y A. Santana (coords.): Destinos turísticos maduros ante el cambio. Reflexiones desde Canarias (pp. 183-213). San Cristóbal de La Laguna, España: Instituto Universitario de Ciencias Políticas y Sociales de la Universidad de La Laguna.

Simancas, M., Dorta, A. y Dávila, H. (2017). La licencia urbanística de obras como indicador de los procesos de renovación de los destinos turísticos maduros de litoral. Boletín de la Asociación de Geógrafos Españoles, 73, 431-452.

Socías, J. (2000). La modernización y reconversión de las zonas turísticas. En Mạ Petit (coord.): Lecciones de derecho del turismo (pp. 119-156). Valencia, España: Tirant lo Blanch.

Sospedra, F. (2013). El deber de conservación del propietario del suelo tras la reforma operada por ley 8/2013. Revista de Urbanismo, 11. Recuperado de https://elderecho.com/el-deber-deconservacion-del-propietario-del-suelo-tras-la-reforma-operada-por-ley-82013

Temes, R. (2007). El tapiz de Penélope. Transformaciones residenciales sobre tejidos sin valor patrimonial (Tesis doctoral). Universidad Politécnica de Valencia.

Temes, R. (2017): La renovación de las ciudades turísticas en Canarias. Una respuesta meditada para unos destinos maduros. Ciudades, 20, 223-243. DOI: http://dx.doi.org/10.24197/ciudades.20.2017.223$\underline{243}$

Vera, F. (2004). Turismo, territorio y medio ambiente. Papeles de Economía Española, 102, 271-286.

ACE, 15 (43) CC BY-ND 3.0 ES | UPC Barcelona, España | Intervenciones de regeneración en áreas turísticas de litoral. 
Vera, F. y Baños, C. (2010). Renovación y reestructuración de los destinos turísticos consolidados del litoral: las prácticas recreativas en la evolución del espacio turístico. Boletín de la Asociación de Geógrafos Españoles, 53, 329-353.

Vera, F., López, F., Marchena, M. y Antón, S. (2011). Análisis territorial del turismo y planificación de destinos turísticos. Valencia, España: Tirant lo Blanch.

Vera, F., Rodríguez, I. y Capdepón, M. (2010). Reestructuración y competitividad en destinos maduros de sol y playa: la renovación de la planta hotelera de Benidorm. En XIII Congreso Internacional de Turismo, Universidad y Empresa. Castellón, España: Universitat Jaume I.

Villalobos, S. (2013). Revistas indexadas y otros vicios académicos. Revista chilena de literatura, 84, 145-153.

Villar, F. (2009). La política turística de Canarias. En M. Simancas (Coord.): El impacto de la crisis en la economía canaria (pp. 469-492). San Cristóbal de La Laguna, España: Real Sociedad económica de Amigos del País / Cabildo de Tenerife.

Villar, F. (2016). Crónica sobre la construcción de un marco legal para la renovación del espacio turístico en Canarias. Práctica Urbanística, 138.

Yepes, V. (1996). Calidad de diseño y efectividad de un sistema hotelero. Papers de Turisme, 20, 137167. 